\title{
Azathioprine induced fever, chills, rash, and hepatotoxicity in rheumatoid arthritis
}

Department of Rheumatology, University Hospital Nijmegen,

The Netherlands M E C Jeurissen A $M$ Th Boerbooms L B A van de Putte

Ziekenhuis Ziekenzorg, Enschede, The Netherlands $M$ W M Kruijsen

Correspondence to: Dr M E C Jeurissen, Department of University Hospital University

Geert Grooteplein Zuid 8, G525 GA Nijmegen, The Netherlands.

Accepted for publication 21 April 1989

\begin{abstract}
Within one year three of 25 patients with rheumatoid arthritis treated with azathioprine $100 \mathrm{mg}$ daily developed the following adverse reactions less than two weeks after starting treatment: patient one showed fever with chills, rash, and severe liver function abnormalities suggestive of cholestasis; the second patient had fever, nausea, diarrhoea, and moderately raised liver enzymes; the third patient showed very high fever and severe chills. In two patients the drug was rechallenged, with more rapidly arising and more severe symptoms. In one case raised liver enzymes persisted until seven months after discontinuation of azathioprine. Hypersensitivity reactions and hepatotoxicity of azathioprine are discussed.
\end{abstract}

Hypersensitivity reactions to azathioprine-for example, fever, myalgia, arthralgia, and rashare well known, but rare, adverse reactions to the drug. ${ }^{1}$ To our knowledge the combination of liver function abnormalities with fever, chills, and rash has been reported before in only two patients. ${ }^{2}$ Recently, we observed in one year three patients with rheumatoid arthritis (RA) treated with $100 \mathrm{mg}$ azathioprine daily who developed fever and chills with liver function abnormalities (two patients) and rash (one patient).

The clinical picture of these three patients is described and allergic adverse reactions to azathioprine and the hepatotoxicity of the drug are discussed.

\section{Case reports}

CASE 1

A 49 year old man was diagnosed as having seropositive RA since 1972. He had been successively treated with parenteral gold and Dpenicillamine. Both drugs were ineffective. For several years he also took diclofenac $150 \mathrm{mg} /$ daily. In April 1988 treatment with azathioprine (100 mg daily) was started because of active RA involving shoulders, elbows, hands, and feet. Laboratory findings were as follows: erythrocyte sedimentation rate (ESR) $42 \mathrm{~mm} / \mathrm{h}$ and haemoglobin $130 \mathrm{~g} / \mathrm{l}$. Apart from an increased concentration of $\operatorname{IgA} 4.5 \mathrm{~g} / 1$ (normal $<2.6 \mathrm{~g} / \mathrm{l}$ ), other laboratory values were normal. Ten days after starting azathioprine he developed fever $\left(38^{\circ} \cdot 5^{\circ} \mathrm{C}\right)$ with severe chills, diarrhoea, and dermatitis of his hands. Azathioprine was discontinued and laboratory values showed a greatly increased ESR of $108 \mathrm{~mm} / \mathrm{h}$, alkaline phosphatase $317 \mathrm{U} / \mathrm{l}$ (normal $<120 \mathrm{U} / \mathrm{l}$ ), and $\gamma$-glutamyltransferase
$176 \mathrm{U} / 1$ (normal $<40 \mathrm{U} / \mathrm{l}$ ). Two days later the clinical situation worsened and he was admitted to hospital. Apart from severe dermatitis of his hands with vesicles and pustules and a moderately active RA, physical examination on admission was normal. Laboratory findings were as follows: ESR $93 \mathrm{~mm} / \mathrm{h}$, haemoglobin $120 \mathrm{~g} / \mathrm{l}$, leucocytes (including eosinophils) and platelets normal. Alkaline phosphatase $810 \mathrm{U} / 1, \gamma-$ glutamyltransferase $295 \mathrm{U} / 1$, serum asparate aminotransferase (AST) $127 \mathrm{U} / 1$ (normal $<25$ $\mathrm{U} / \mathrm{l}$ ), serum alanine aminotransferase (ALT) $150 \mathrm{U} / 1$ (normal $<30 \mathrm{U} / \mathrm{l}$ ). Bilirubin total and direct slightly raised at 26 and $18 \mu \mathrm{mol} / \mathrm{l}$ (normal $<10 \mu \mathrm{mol} / 1$ and $1 \mu \mathrm{mol} / 1$ respectively), lactic dehydrogenase and amylase normal. Blood cultures showed no growth. Tests for syphilis, hepatitis A and B, and cytomegalovirus were negative. Antinuclear antibody, antibodies against mitochondria and smooth muscle were also negative. HLA typing: A2, B5, B15, Bw62, Bw4, Bw6, DR4, DRw52, DQw2, DQw3. Ultrasonography of gall bladder, biliary tract, liver, and pancreas was normal.

Because all liver enzymes rose further (maximum alkaline phosphatase 935 U/l, AST 290 U/l) a liver biopsy was performed. Histological examination showed only some (peri)portal infiltration and several necrotic liver cells, but neither cholestasis nor cirrhosis. The figure shows the course of the liver function tests. He was dismissed with diclofenac $150 \mathrm{mg}$. In July 1988 the RA was more active and prednisone $7.5 \mathrm{mg}$ daily was started. The liver enzymes normalised only seven months after dismissal.

CASE 2

A 63 year old woman had been suffering from seropositive RA since 1977. Besides indomethacin $150 \mathrm{mg}$ daily she had been treated with hydroxychloroquine sulphate, D-penicillamine (thrombocytopenia), oral gold tablets (ineffective), and sulphasalazine (fever, exanthema). She refused parenteral gold treatment. In March 1987 she was admitted to hospital because of active RA involving knee, hands, wrists, and shoulders. The ESR was $97 \mathrm{~mm} / \mathrm{h}$, haemoglobin $115 \mathrm{~g} / \mathrm{l}, \mathrm{IgA} 4.9 \mathrm{~g} / 1, \mathrm{IgG} 16.3 \mathrm{~g} / 1$ (normal $<14.6$ $\mathrm{g} / \mathrm{l})$. Other laboratory findings were normal. HLA typing: A2, Aw19, B13, B15, Bw4, Bw6, DR4, DR7, DRw53, DQw2, DQw3.

Thirteen days after starting azathioprine 100 mg daily she developed fever $\left(39^{\circ} \mathrm{C}\right)$, nausea, vomiting, and diarrhoea. Blood tests showed raised alkaline phosphatase $(240 \mathrm{U} / \mathrm{l})$ and $\gamma$ glutamyltransferase $(76 \mathrm{U} / \mathrm{l})$. Blood cell counts were unchanged. Transaminase and amylase 


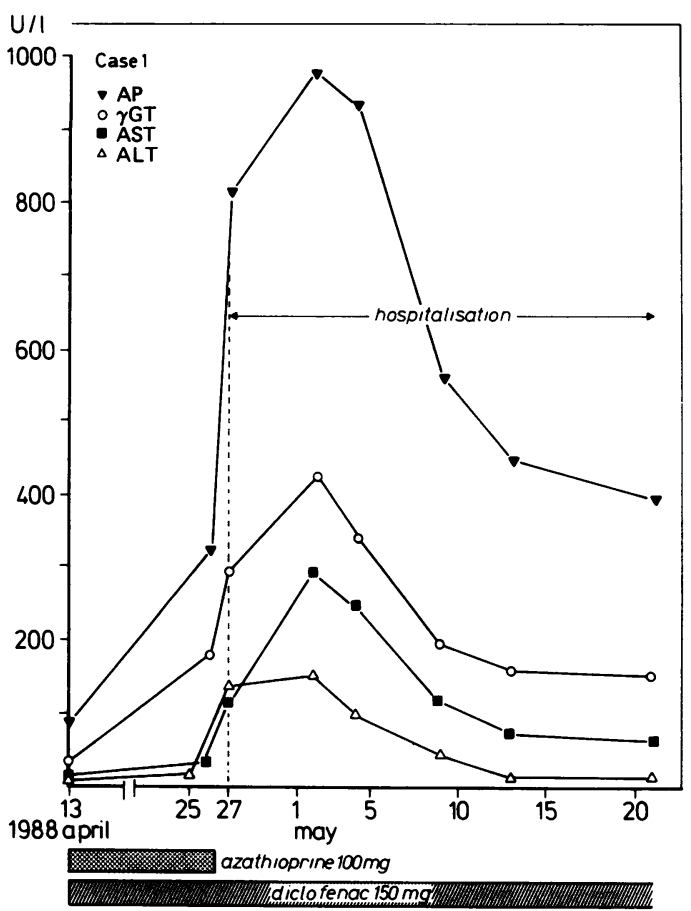

Changes of liver function tests (alkaline phosphatase (AP), $\gamma$-glutamyltransferase $(\gamma G T)$, serum aspartate aminotransferase (AST), serum alanine aminotransferase (ALT)) during treatment of patient No 1 with azathioprine and diclofenac.

were normal. Blood cultures showed no growth. Ultrasonography of the abdomen was normal. Azathioprine was discontinued. Five days later one tablet of azathioprine was given by accident and within two hours diarrhoea and fever $\left(39.5^{\circ} \mathrm{C}\right)$ again occurred. Liver enzymes returned to normal in two weeks. She was successfully treated with $15 \mathrm{mg}$ methotrexate orally weekly. This drug caused no liver dysfunctions.

\section{CASE 3}

A 74 year old woman was diagnosed as suffering from seropositive RA since 1984 . Besides diclofenac $100 \mathrm{mg}$ daily she had been treated with parenteral gold for one year and D-penicillamine $750 \mathrm{mg}$ daily for 18 months. Both drugs were ineffective. In October 1987 azathioprine 100 mg daily was started because of active RA involving wrists, hands, left shoulder, and jaws. Laboratory findings showed an ESR of 30 $\mathrm{mm} / \mathrm{h}, \mathrm{C}$ reactive protein $51.0 \mathrm{mg} / \mathrm{l}$ (normal $<6.0 \mathrm{mg} / \mathrm{l}$ ), haemoglobin $125 \mathrm{~g} / \mathrm{l}$. Apart from a diminished renal function (estimated creatinine clearance $60 \mathrm{ml} / \mathrm{min})$ and raised $\operatorname{IgA}(4 \cdot 1 \mathrm{~g} / \mathrm{l})$ and $\operatorname{IgG}(21.6 \mathrm{~g} / \mathrm{l})$, other laboratory values were normal. HLA typing: A2, A29, B12, B27, Bw4, Bw6, DR4, DRw53, DQw3.

On the 13th day of azathioprine treatment she showed fever $\left(38.5^{\circ} \mathrm{C}\right)$, dry cough, and some nausea. Laboratory studies showed slight leucopenia $\left(3 \cdot 1 \times 10^{9} / 1\right)$ with normal differential count. A viral infection was suspected and azathioprine was temporarily discontinued. Two weeks later azathioprine was restarted. Within two hours of taking one tablet severe fever $\left(41.5^{\circ} \mathrm{C}\right)$ with chills occurred which necessitated hospital admission. Examination showed no hypotension and no other findings to explain the high fever. Repeated blood tests showed an ESR of 35 $\mathrm{mm} / \mathrm{h}$. Leucocytes, differential count, and liver function tests were normal. Blood cultures showed no growth and a chest radiograph was normal. Two days after admission and discontinuation of azathioprine she was afebrile. Treatment with oral methotrexate $(7.5 \mathrm{mg}$ weekly) had to be discontinued five months later because of stomatitis and dermatitis.

\section{Discussion}

Our finding of azathioprine hypersensitivity reactions in three of 25 (12\%) patients with $R A$ followed up for one year is remarkable. Bell et al (ARA meeting, Houston, May 1988) have also reported a high percentage of azathioprine hypersensitivity reactions $(4 / 17 ; 24 \%)$. The presence of these side effects in larger numbers of patients with RA, our own previous study included, was between $<1 \%$ and $5 \%$. $^{1345}$ To our knowledge the triad (severe liver function abnormalities, rash, fever with chills), as shown in patient 1 , has been reported only once before in two out of a series of 50 patients with RA. Hypersensitivity reactions or hepatotoxicity, or both, due to azathioprine have also been reported in patients with diseases other than RA. ${ }^{6-10}$ Although a genetic predisposition to azathioprine toxicity is speculative, we found a striking similarity of HLA typing in patients 1 and 2, both having the phenotypes $\mathrm{A} 2, \mathrm{~B} 15, \mathrm{Bw} 4$, Bw6, DR4, DQw2, DQw3. Patient 3 also had these phenotypes except B15 and DQw2. In 171 other patients with RA treated with different drugs we did not find the HLA typing of cases 1 and 2. We could not confirm an association between a low IgA concentration and azathioprine hepatotoxicity ${ }^{11}$ because the patients we described all had repeatedly raised IgA concentrations.

Hypersensitivity reactions to azathioprine have been found to occur mostly within two weeks of starting treatment. ${ }^{2} 6$ That inverval was also seen in our three patients.

Hepatotoxicity associated with azathioprine can develop between two weeks and 33 months after starting treatment, ${ }^{6} 8$ possibly depending on the origin of hepatotoxicity. The mechanisms of azathioprine hepatotoxicity may be threefold-namely (a) allergic (with simultaneous systemic allergic symptoms); (b) direct hepatotoxic (exact mechanism unknown ${ }^{12}$ ); (c) blockade of the liver blood outflow at the junction of sinusoids and centrilobular veins, causing peliosis hepatitis. ${ }^{13}$ Davis et al have suggested that the imidazole moiety of azathioprine causes the allergic symptoms and the 6-mercaptopurine moiety the liver injury. ${ }^{10}$ Histologically, the picture of azathioprine hepatotoxicity consists of intrahepatic cholestasis with variable degrees of liver cell necrosis and slight (peri)portal inflammatory reaction. Biochemically, abnormal liver function tests are found, ranging between a cholestatic pattern and increase of transaminase. ${ }^{6}$ Azathioprine hepatotoxicity is mostly a reversible process, but normalisation of liver enzymes can take several months, ${ }^{8}$ as shown in patient 1 . For different reasons it 
seems unlikely that diclofenac had a role in the production of liver dysfunctions in patient 1 . Firstly, he had already used that drug for several years without side effects. Secondly, liver function returned to normal (very slowly) while treatment with diclofenac was continuing. Thirdly, the pattern of liver enzyme increase (cholestatic) is unusual for diclofenac hepatotoxicity. ${ }^{14}$

Reintroduction of a smaller dose of azathioprine in dose related hepatotoxicity seems justified, ${ }^{9}$ but rechallenge of azathioprine when there is a suspicion of hypersensitivity can be dangerous and lead to life threatening shock. ${ }^{15-17}$ In patient 2 the reintroduction of azathioprine was not our intention but happened accidentally. Retrospectively, the first period of fever and malaise in patient 3 was not recognised as azathioprine toxicity. If there is a compelling reason for reintroducing azathioprine it must be done under very careful clinical observation. ${ }^{17}$ For completeness we point out that the spectrum of azathioprine hypersensitivity can include more symptoms. ${ }^{18}$

In summary, with these three case reports of azathioprine hypersensitivity in patients with RA we draw attention to this serious complication and recommend that liver function tests are carried out two weeks after starting azathioprine and thereafter every one to two months.

\section{Addendum}

Very recently we saw a new case of severe azathioprine hypersensitivity in a patient whose clinical picture was similar to that of patient 1 .

The patient, a 27 year old man who had had destructive seropositive RA since 1983, was admitted to hospital because of fever $\left(39 \cdot 2^{\circ} \mathrm{C}\right)$, chills, nausea, cough, and purpura on his legs. He had taken azathioprine $100 \mathrm{mg}$ for 12 days and piroxicam $20 \mathrm{mg}$ daily for several years. Both drugs were discontinued. Laboratory investigation of this severely ill patient disclosed an ESR of $126 \mathrm{~mm} / \mathrm{h}(78 \mathrm{~mm} / \mathrm{h}$ ), (figures in brackets show the values before the start of azathioprine treatment), haemoglobin $101 \mathrm{~g} / 1$ $(127 \mathrm{~g} / \mathrm{l})$, leucocytes $27 \times 10^{9} / 1\left(11 \cdot 8 \times 10^{9} / 1\right)$ with shift to the left in the differential count, bilirubin total $63 \mu \mathrm{mol} / \mathrm{l}$, direct $46 \mu \mathrm{mol} / \mathrm{l}$, azathioprine $422 \mathrm{U} / \mathrm{l}$ (77 U/l), $\gamma$-glutamyltransferase $73 \mathrm{U} / 1$, ALT $87 \mathrm{U} / 1$ (8 U/l), AST $32 \mathrm{U} / 1$ (11 U/1). Chest radiograph was normal. Blood cultures showed no growth. All serological tests (see patient 1) were negative. Because all liver enzymes rose further in three weeks (alkaline phosphatase $800 \mathrm{U} / 1, \gamma$-glutamyltransferase 175
U/l, ALT 192 U/l, AST 63 U/l) a liver biopsy was performed, which disclosed a moderate portal infiltration of eosinophil leucocytes around small bile canaliculi (without bile stasis). Sporadic necrotic liver cells were present. A skin biopsy showed aspecific perivascular inflammation. Six weeks after admission this patient is still in hospital (May 1989) and liver enzymes are still greatly raised (alkaline phosphatase 900 $\mathrm{U} / 1, \gamma$-glutamyltransferase $254 \mathrm{U} / \mathrm{l}$, ALT 148 U/1). HLA typing: Aw19, B15, B40, Bw6, DR4, DQw3. We are grateful to Dr M Kruijsen (Ziekenhuis Ziekenzorg,
Enschede, The Netherlands) for allowing us to study his Enschede, The Netherlands) for allowing us to study his
patients, and we wish to thank Mrs Marion Janssen for her patients, and we wish to
excellent secretarial help.

1 Whisnant J K, Pelky J. Rheumatoid arthritis: treatment with azathioprine (Imuran $(\mathbf{R})$ ). Clinical side effects and laboraazathioprine (Imuran (R)). Clinical side effects and labora2 Stollenwerk R, Schilling F. Imurek-Fieber. Verh Disch Ges Rheromatol 1980; 6: 473-4.

3 Speerstra F, Boerbooms A M Th, van de Putte L B A, van Beusekom H J, Kruijsen M W M, Vandenbroucke J P. Side effects of azathioprine treatment in rheumatoid arthritis: analysis of 10 years of experience. Ann Rheum Dis 1982; 41 37-9.

4 Paulus H E, Williams H J, Ward J R, et al. Azathioprine versus D-penicillamine in rheumatoid arthritis patients who have been treated

5 Hamdy H, McKendry R J R, Mierins E, Liver J A. Low dose methotrexate compared with azathioprine in the treatmen of rheumatoid arthritis. A twenty-four week controlled clinical trial. Arthritis Rheum 1987; 30: 361-8.

6 Kissel J T, Levy R J, Mendell J R, Griggs R C. Azathioprine toxicity in neuromuscular diseases. Neurology 1986; 336 35-9.

7 Singleton J W, Law D H, Kelly M L, Mekhjian H S, Sturdevant R A L. National cooperative Crohn's disease study: adverse reactions to study drugs. Gastroenterology 1979; 77: 870-82.

8 Iselin H, Knoblauch M, Binswanger K, et al. Aazathioprininduzierte intrahepatische cholestase. Schweiz Med induzierte intrahepatische

9 Ware A J, Luby J P, Hollinger B, et al. Etiology of liver disease in renal transplant patients. Ann Intern Med 1979; 91: 364-71.

10 Davis M, Eddlestone A L W F, Williams R. Hypersensitivity and jaundice due to azathioprine. Postgrad Med F 1980; 56 : 274-5.

11 Harvey C, Dixon J S, Bird H A. Serum IgA concentration and hepatotoxicity in rheumatoid arthritis treated with azathioprine. $B r$ Med F 1983; 287: 534.

12 Menard D B, Gisselbrecht C, Marty M, Reyes F, Dhumeaux D. Antineoplastic agents and the liver. Gastroenterology 1980; 78: 142-64.

13 Degott C, Rueff B, Kreis H, Duboust A, Potet F, Benkamou J P. Peliosis hepatitis in recipients of renal transplants. Gut 1978; 19: 748-53.

14 Paulus H E. FDA arthritis advisory committee meeting: serious gastrointestinal toxicity of non-steroidal antiinflammatory drugs; drug-containing renal and biliary stones; diclofenac and carprofen approved. Arthritis Rheum 1988; 31: 1450-1.

15 Cunningham T, Barraclough D, Muirdin K. Azathioprineinduced shock. Br Med 7 1981; 283: 823-4.

16 Keystone E C, Schabas R. Hypotension with oliguria: a side effect of azathioprine. Arthritis $R$ heum $1981 ; 24: 1453-4$

17 Rosenthal E. Azathioprine shock. Postgrad Med F 1986; 62: 677-8.

18 Saway P A, Heck L W, Bonner J R, Kerklin J K Azathioprine hypersensitivity. Case report and review of the Azathioprine hypersensitivity. Case report
literature. Am f Med 1988; 84: $960-4$. 